\title{
Analisis Dan Pengembangan Sistem Informasi Bisnis Dengan Pemodelan Arsitektur Enterprise Zachman Framework Pada PT. Deliv Tehnologi Indoraya
}

\author{
Ahmad Riza, Zaki Mukhammad, M. Fahmi Alaudin
}

\begin{abstract}
Information system architecture is a model in looking at the components involved as a whole in the organization. Zachman framework is a framework for information system architecture that provides an overview of the results of information system architecture. Understanding this framework is useful in determining which method of information system architecture will be used. The Zachman Framework Enterprise Architecture is one method for developing information systems architecture. This study explains the relationship with artifacts on the Zachman Framework, in the stages of making information systems architecture based on the Zachman framework method. Case study research place at PT. Indoraya Technology Deliv. The results of the case study in the form of an information system architecture document as a basis for the development of information systems at PT. Indoraya Technology Deliv.
\end{abstract}

Keywords: Enterprise Architecture; Informatiton System; Zachman Framework

Abstrak - Arsitektur sistem informasi merupakan permodelan dalam memandang dari komponen-komponen yang terlibat secara keseluruhan di organisasi. Zachman framework adalah salah satu framework untuk arsitektur sistem informasi yang memberikan gambaran hasil dari arsitektur sistem informasi. Pemahaman framework ini berguna dalam menentukan metoda arsitektur sistem informasi yang mana akan dipakai. Enterprise Architecture Zachman Framework merupakan salah satu metode untuk mengembangkan arsitektur sistem informasi. Penelitian ini menjelaskan keterkaitannya dengan artifak-artifak pada Zachman Framework, dalam tahapan pembuatan arsitektur sistem informasi berdasarkan metode Zachman framework. Tempat penelitian studi kasus di PT. Deliv Tehnologi Indoraya. Hasil studi kasus berupa dokumen arsitektur sistem informasi sebagai landasan bagi pengembangan sistem informasi di PT. Deliv Tehnologi Indoraya.

Kata kunci: Enterprise Architecture; Sistem Informasi; Zachman Framework.

Ahmad Riza Author is with the Informatic Engineering Departement of Maulana Malik Ibrahim Islamic State University, Malang, Indonesia (email ahmadriza718@gmail.com )

Zaki Mukhammad Author was with the Informatic Engineering Departement of Maulana Malik Ibrahim Islamic State University, Malang, Indonesia(e-mail: zakimuhammad20@gmail.com).

M. Fahmi Alaudin Author was with the Informatic Engineering Departement of Maulana Malik Ibrahim Islamic State University, Malang, Indonesia

\section{PENDAHULUAN}

$\mathrm{P}$ erubahan lingkungan dan kebutuhan dari bisnis berubah secara cepat yang memaksa manajemen eksekutif untuk memiliki informasi yang up to date setiap waktunya, sehingga mereka bisa mengelola bisnisnya dengan lebih efektif. Perusahaan harus bisa membuat ketersedian inforamasi dalam tingkat organisasi, bukan hanya dalam tingkat unit bisnis. Pengoptimalan informasi dalam tingkat organisasi mensyaratkan integrasi kesemua informasi yang dimiliki unit-unit bisnis.

PT. Deliv Tehnologi Indoraya merupakan perusahaan teknologi yang memberikan layanan dibidang teknologi. Contoh layanan yang ditawarkan adalah layanan antar makanan dengan bekerja sama dengan mitra restoran dan driver yang telah terdaftar dan juga terdapat layanan ojek online. PT. Deliv Tehnologi bukanlah perusahaan transportasi tapi hanya memberikan platform teknologi sebagai perantara antara penyedia jasa dan customer.

PT. Deliv Tehnologi Indoraya sebagai salah satu perusahaan teknologi tidak terlepas dari tuntutan peningkatan daya saing, sehingga dibutuhkan tata kelola sistem yang lebih baik. Tata kelola di perusahaan ini meliputi pengelolaan sistem IT, sumber daya manusia, keuangan, dan pemasaran. Dalam melakukan pengelolaan ini, tidak terlepas dari dukungan teknologi informasi dan komunikasi. Tata kelola yang berisi proses bisnis dan implementasi teknologi informasi dalam lingkup organisasi ini dikenal juga sebagai arsitektur enterprise [1]. Setelah suatu organisasi memiliki tata kelola yang baik, permasalahan belum dapat dikatakan selesai. Namun juga perlu memperhatikan tahapan implementasi dari teknologi informasi dan komunikasi yang mewujudkan pencapaian strategi bisnis dari organisasi. Keselarasan dalam penerapan teknologi dan strategi bisnis diharapkan akan meningkatkan efesiensi, mengurangi biaya operasional, meningkatkan hubungan dengan stakeholder, serta menghasilkan solusi bisnis [2].

Tujuan dari penelitian ini yaitu untuk menganalisis sistem informasi PT. Deliv Tehnologi Indoraya dalam 
proses bisnis organisaogi Indoraya dalam proses bisnis organisasi. Selain itu juga untuk mengembangkan sistem informasi akademik dengan metede Enterprise Architecture yang baik dan dapat diterapkan pada PT. Deliv Tehnologi Indoraya.

Kemudian kontribusi yang diharapkan peneliti dari penelitian ini adalah pertama memberikan rekomendasi serta usulan metode yang dapat digunakan dalam pengembangan sistem informasi pada PT. Deliv Tehnologi Indoraya. Kedua menghasilkan suatu kebijakan strategis yang baik dan cocok dengan kondisi di lingkungan PT. Deliv Tehnologi Indoraya. Ketiga adanya panduan pengembangan sistem informasi dari organisasi sehingga mendapatkan dukungan dari pihak manajemen bukan merupakan bentuk kebutuhan sesaat saja. Terakhir dapat diketahui posisi sistem informasi dalam pemberdayaan dan penerapan secara lebih efektif dan efisien, Sehingga pengembangan strategis ini dapat menjadi panduan Pengembangan sistem Informasi selanjutnya.

\section{LANDASAN TEORI}

\subsection{Konsep Sistem Informasi}

Sistem informasi merupakan pengaturan data, orang, proses, dan informasi atau teknologi informasi yang berinteraksi untuk mengumpulkan, memproses, menyimpan, dan menyediakan sebagai output informasi yang diperlukan untuk mendukung sebuah instansi atau organisasi [3]. Untuk dapat mendukung proses bisnis yang dijalankan oleh PT. Deliv Tehnologi Indoraya sebagai perusahaan yang memiliki keunggulan dalam persaingan dengan ritel-ritel perhiasan lainnya, maka perusahaan tersebut sebaiknya menerapkan SI/TI yang dapat membantu aktivitas proses bisnis di perusahaan tersebut sehingga dapat meningkat secara bertahap menuju peranan yang lebih strategis [4][5]. Dalam hal ini SI/TI yang diterapkan haruslah memperhatikan suatu proses pembangunan sistem serta perencanaan yang matang dengan memperhatikan semua kepentingan setiap pihak yang terlibat dengan sistem tersebut, baik itu pihak managemen sebagai pihak yang bertanggung jawab terhadap kinerja organisasi, pihak pengembang yang bertanggung jawab terhadap sistem yang dibangun, maupun pengguna yang bertanggung jawab terhadap pemanfaatan sistem yang sedang dibangun [6].

\subsection{Enterprise Arsitecture}

Enterprise Architecture (EA) adalah model komprehensif suatu perusahaan, rencana induk, yang bertindak sebagai perencanaan, penataan, dan pengintegrasian pedoman dan kekuatan bagi suatu organisasi [7]. EA mencakup struktur dan konteks bisnis, dimensi teknologi informasi dan struktur organisasi, dan dimensi alur kerja dalam mencapai tujuan dan strategi organisasi. Ini berusaha untuk mempromosikan sinergi antara berbagai dimensi, selaras dengan mencapai tujuan bisnis secara keseluruhan. EA sendiri merupakan pendekatan modern untuk melakukan perencanaan terhadap kualitas data dan mencapai misi SI serta proses yang dilakukan untuk mendukung bisnis dan rencana implementasi pada bidang arsitektural dan startegis yang meliputi informasi, sistem bisnis dan arsitektur Teknik [8].

\subsection{Zachman Framework}

Zachman merupakan salah satu metode Enterprise Architecture Framework, yang memberikan pengetahuan tentang langkah-langkah pengembangan penjualan dengan arsitektur yang sistematis. Dengan kerangka kerja ini, kerangka kerja dapat mengetahui kolom berdasarkan kolom dalam kerangka kerja Zachman. Kolom dari Zachman Framework mendefinisikan fokus yang berbeda-beda atau menggambarkan abstraksi produk dari berbagai perspektif. Tiap fokus mengacu pada sebuah pertanyaan dimana cara pertanyaan itu dijawab sangat tergantung pada perspektif. Dengan kata lain, perspektif mengharuskan bentuk dan rincian yang diperlukan untuk membuat setiap pertanyaan menjadi jelas dan dimengerti [9].

Gambar 1 dibawah menjelaskan bahwa Zachman Framework ini harus meliputi 6 kategori yaitu sebagai berikut:

1. What,

2. Why,

3. Where,

4. Who,

5. When, dan

6. How.

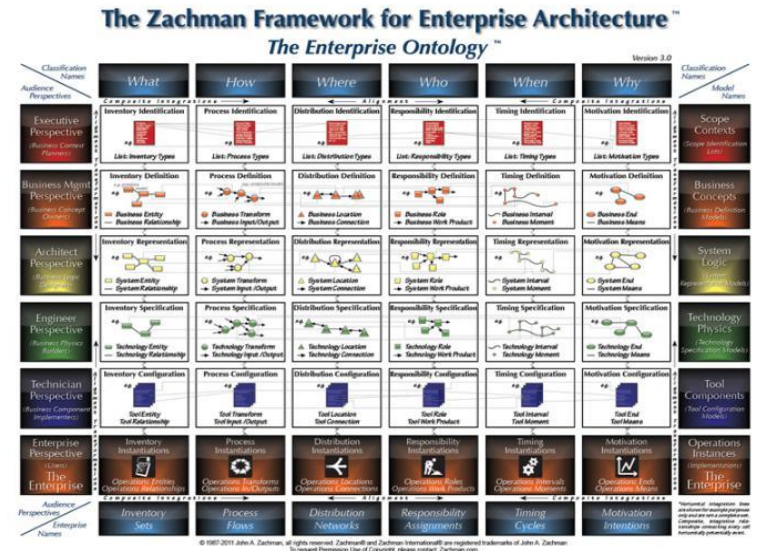

Gambar 1. Zachman Framework

Setiap baris pada kerangka kerja Zachman Framework mewakili perspektif yang berbeda yaitu:

1. Scope/Planner/Perencana : yang menetapkan objek dalam pembahasan; latar belakang, lingkup, dan tujuan enterprise.

2. Business Model/Business Owner/Pemilik : penerima atau pemakai produk/jasa akhir dari enterprise.

3. System Model/Designer/Perancang : perantara antara apa yang diinginkan (pemilik) dan apa yang dapat dicapai secara teknis dan fisik.

4. Technology Model/Builder/ Pembangun : pengawas atau pengatur dalam menghasilkan produk/jasa akhir. 
5. Detailed Representation /Subkontraktor bertanggung jawab membangun dan merakit bagian-bagian dari produk/jasa akhir.

6. Functional Areas atau Functioning system/Functioning enterprise : wujud nyata dari produk/jasa akhir

Zachman Framework merupakan logika terstruktur untuk pengklasifikasian dan pengorganisasian tipe-tipe dokumen, rancangan atau model yang merepresentasikan

Sebuah perusahaan. Zachman Framework bukan metodologi untuk mengembangkan suatu arsitektur enterprise. Zachman Framework bersifat kategorisasi artefak Enterprise Architecture. Zachman Framework hanya berupa thingking tool yang membantu arsitek dan manajermengisolasikan masalah dan mengatur apa saja yang perlu diurus.

\subsection{UML}

Unified Modeling Language (UML) merupakan bahasa spesifikasi standar yang digunakan untuk melakukan kegiatan dokumentasi, menspesifikasi dan membangun perangkat lunak [10]. UML adalah metodologi dalam mengembangkan sistem berorientasi objek dan juga alat untuk mendukung pengembangan sistem. Alat bantu yang digunakan dalam perancangan berorientasi objek berbasiskan UML salah satunya adalah Use Case Diagram. Use Case Diagram adalah pemodelan untuk kelakuan (behavior) sistem informasi yang akan dibuat. Use case digunakan untuk mengetahui fungsi-fungsi yang ada di dalam sistem informasi dan siapa saja yang berhak untuk menggunakan fungsi-fungsi tersebut. Berikut contoh dari Use Case Diagram :

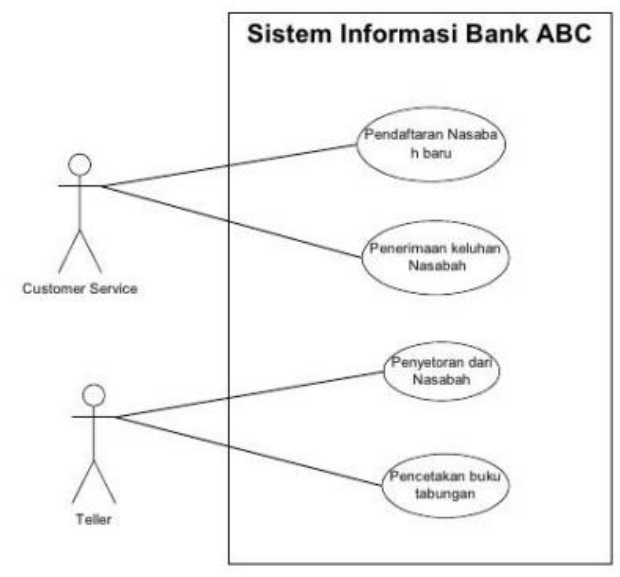

Gambar 2. Use Case Diagram

\subsection{Prototipe}

Prototipe adalah suatu proses dalam membangun sebuah model yang menunjukkan fitur dari produk yang diusulkan, layanan atau sistem [11]. Dalam membangun sebuah model yang sesuai dengan kebutuhan dasar bisnis, maka prototipe memungkinkan pengguna untuk melihat, bekerja dengan, dan mengevaluasi model dengan menyarankan perubahan pada model yang meningkatkan kemungkinan sebuah keberhasilan diusulkan.

\section{METODE PENELITIAN}

\subsection{Bahan Penelitian}

Bahan penelitian yang dibutuhkan dalam perencanaan strategis sistem informasi ini adalah :

1. Strategi bisnis organisasi PT. Deliv Tehnologi Indoraya yang didalamnya terdapat Visi, Misi, Tujuan dan sasaran organsisasi.

2. Kondisi lingkungan eksternal dan internal bisnis organisasi.

3. Lingkungan eksternal dan internal sistem informasi dan teknologi informasi organisasi.

4. Proses bisnis dari sistem informasi yang sudah ada.

5. Infrastruktur teknologi informasi.

Memperoleh bahan-bahan diatas dilakukan melalui pengamatan, wawancara dan serta pengumpulan dokumen-dokumen yang terkait dengan analisis dan pengembangan sistem informasi.

\subsection{Alat Penelitian}

Penelitian ini menggunakan alat dan tools sebagai berikut :

1. Zachman Framework, menyediakan dasar yang menunjang struktur organisasi, akses, integrasi, interpretasi, pengembangan, manajemen serta perubahan representasi arsitektur dari sistem informasi organisasi. Setiap obyek atau deskripsi dari representasi arsitektur direferensikan sebagai artifak.

a. Kolom What membahas tentang data yang ada di PT. Deliv Tehnologi Indoraya. Pada kolom What, bagian yang akan dijelaskan yaitu scope, Bussiness Model, dan system model.

b. Kolom How membahas tentang proses-proses yang terjadi di PT. Deliv Tehnologi Indoraya. Pada kolom How, bagian yang akan dijelaskan yaitu scope, Bussiness Model, system model dan technology model.

c. Kolom Where membahas tentang lokasi bisnis utama dari PT Deliv Tehnologi Indoraya. Pada kolom Where, bagian dijelaskan yaitu scope, Bussines Model, system model, dan technology model.

d. Kolom Who membahas tentang sumber daya manusia yang berperan di PT. Deliv Tehnologi Indoraya. Pada kolom Who,bagian yang akan dijelaskan yaitu scope, Bussines Model, system model, technology model, components dan functional system.

e. Kolom When membahas tentang pendefinisian kegiatan dan alokasi penggunaan waktu untuk kegiatan yang dilakukan oleh PT. Deliv Tehnologi Indoraya. Pada kolom When, bagian yang akan dijelaskan yaitu scope, Bussines Model, system model, dan functioning system.

f. Kolom Why membahas tentang hal-hal yang ingin dicapai oleh PT. Deliv Tehnologi Indoraya. Pada 
kolom Why, bagian yang akan dijelaskan yaitu scope danBussines Model.

2. Website untuk membuat UML (Unified Modelling Language ) yaitu www.draw.io yang lebih memudahkan dalam membuat UML.

\section{HASIL DAN PEMBAHASAN}

Hasil dan Pembahasan penelitian ini sebagai berikut:

\subsection{What}

Dalam kolom What mengenai data yang tersedia di PT. Deliv Tehnologi Indoraya. Bagian-bagian yang akan diuraikan adalah scope, mengenai proses-proses Bisnis yang terjadi di PT. Deliv Tehnologi Indoraya. Bagian-bagian yang akan dijelaskan yaitu scope, dan Business Model.

a. Scope

Uraian mengenai daftar nama entitas yang berperan penting dalam proses bisnis di PT. Deliv Tehnologi Indoraya, penguraian dilakukan secara tekstual. PT. Deliv Tehnologi Indoraya memiliki entitas bisnis, yaitu:

1. Pejabat Struktural, yaitu: BOD, CEO, CTO, CFO, WP Pemasaran, dan Penasihat.

2. Manajer yang dibawahi oleh CTO, CFO, dan WP Pemasaran.

3. Para Staf.

4. Mitra Driver

5. Mitra Restoran

6. Pelanggan

b. Business Model

Bussiness Model PT. Deliv Tehnologi Indoraya mengenai kebutuhan data para entitas. Enjelasan Relasional Entitas Bisnis, sebagai berikut:

1. Pejabat struktural membuat rencana bisnis perusahaan yang ada di PT. Deliv Tehnologi Indoraya.

2. Manajer membantu tugas CTO, CFO, dan WP Pemasaran serta pengordinasi para staf yang dibawahinya.

3. Staf menjalankan bisnis yang telah direncanakan oleh para pejabat struktural.

4. Mitra Driver melayani pelanggan yang membuat order dan wajib untuk menyelesaikannya.

5. Mitra Restoran mendaftarkan restorannya di sistem deliv agar bisa diakses diaplikasi.

6. Pelanggan dapat membuat order sesuai keinginan.

\subsection{How}

Dalam kolom How membahas tentang proses-proses Akademik yang ada di PT. Deliv Tehnologi Indoraya. Bagian-bagian yang akan dijelaskan yaitu scope, Bussiness Model, system model, dan technology model. a. Scope
Proses-proses utama dalam bisnis yang terjadi di PT. Deliv Tehnologi Indoraya yaitu:

1. Pemesanan deride, defood, dan decar.

2. Pembayaran layanan yang telah diberikan.

3. Pendaftaran mitra driver dan defood.

4. Kewajiban mitra untuk menyelesaikan pesanan yang didapatkan.

\section{b. Bussiness Model}

Bussiness Model PT. Deliv Tehnologi Indoraya mengenai kebutuhan data para entitas. Penjelasan Relasional Entitas Bisnis, sebagai berikut:

1. Pelanggan melakukan pemesanan Deride, Decar, atau Defood sesuai kebutuhan.

2. Pelanggan akan mendapatkan driver yang akan menyelesaikan order.

3. Driver wajib menyelesaikan order sesuai pesanan.

4. Driver wajib mengantarkan pesanan ke alamat pelanggan jika pelanggan memesan makanan lewat defood, jika pelanggan memesan deride atau decar driver wajib menjemput dan mengantarkan pelanggan sesuai titik yang dipesan pelanggan.

5. Pelanggan wajib membayar layanan yang telah diberikan sesuai total pembayaran yang tertera di sistem.

\section{c. Desain Sistem Use Case Layanan Deliv}

Berikut ini merupakan deskripsi dari sekumpulan aksi yang dilakukan pengguna Deliv. Sekumpulan aksi tersebut digambarkan menggunakan Use Case Diagram.

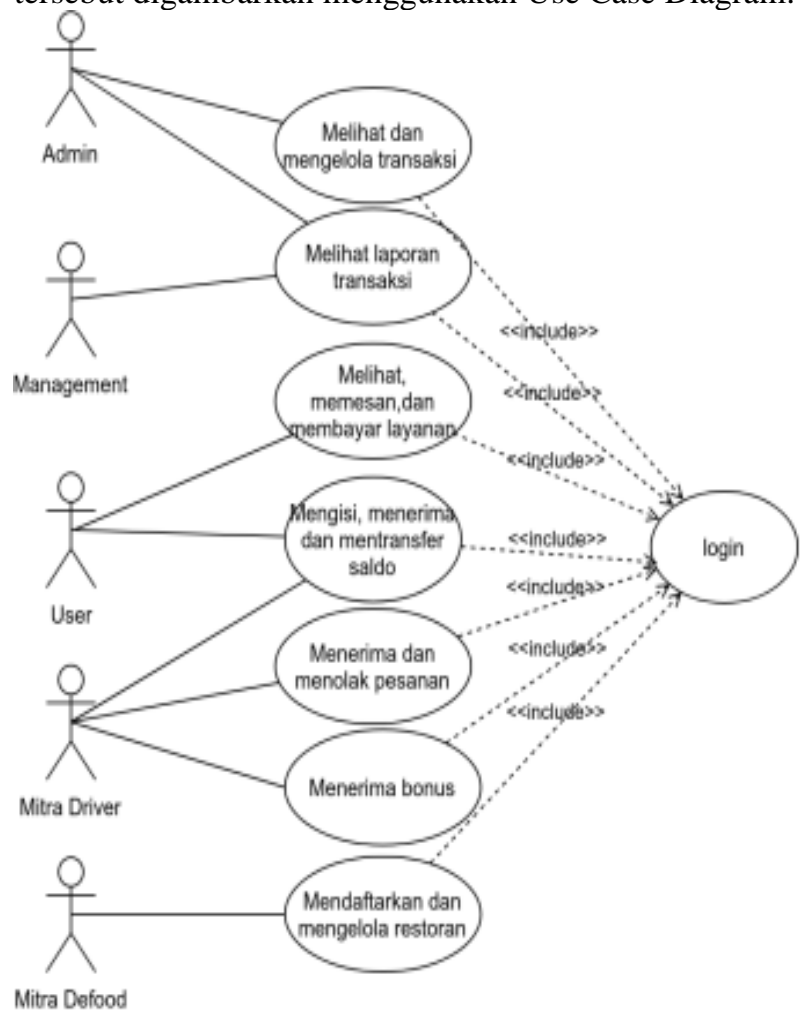

Gambar 3. Use Case Diagram Sistem 


\section{d. Teknologi Model}

Prototipe sistem bertujuan untuk memberikan gambaran tentang bagaimana sistem akan berfungsi ketika telah tersusun dalam bentuk yang lengkap. Adapun tampilan prototipe aplikasi deliv dapat dilihat sebagai berikut:

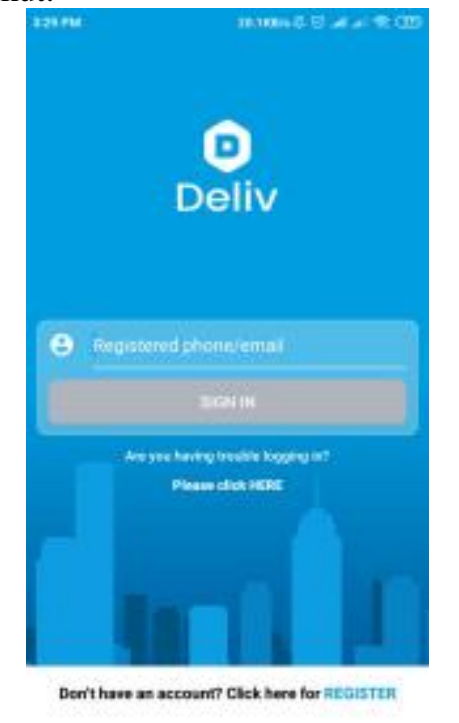

Gambar 4. Tampilan Halaman Login

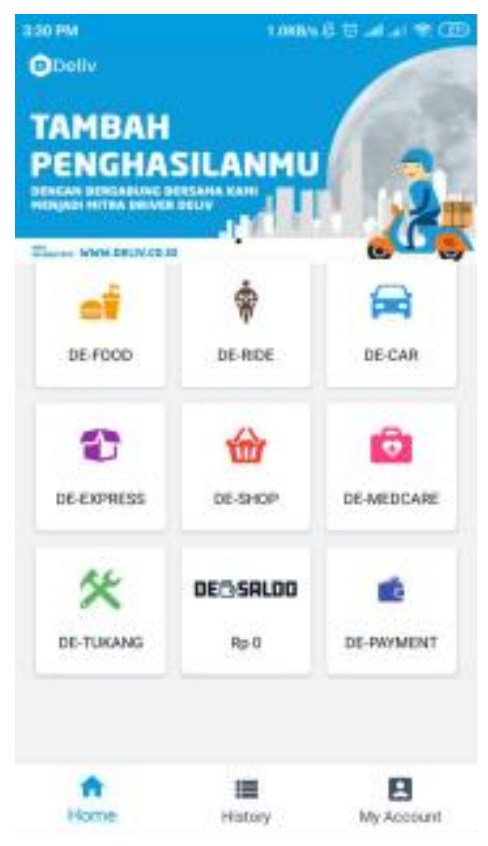

Gambar 5. Tampilan Halaman Awal Aplikasi

\subsection{Where}

Membahas mengenai lokasi bisnis utama PT. Deliv Technology Indoraya dalam menjalankan proses kegiatan bisnis dan pengembangan. Bagian yang akan dijelaskan yaitu scope, Business model, system model, dan technology model.

a. Scope

Berikut ini merupakan daftar lokasi bisnis PT. Deliv Technology Indoraya berjalan:

1. Kantor Riset dan Pengembangan di Villa Sengkaling Blok T No. 4, Malang - Jawa Timur.

2. Kantor Pusat Bisnis berada di Kabupaten Bojonegoro - Jawa Timur.
3. Lokasi bisnis berjalan di Kabupaten Bojonegoro, Kabupaten Tuban, dan Kota Tarakan.

4. Server berada di virtual private server (VPS) Amazon Web Service (AWS).

b. Business Model

Bagian Business model menggambarkan peta lokasi bisnis PT. Deliv Technology Indoraya berjalan yang berada di Kabupaten Bojonegoro, Kabupaten Tuban, dan Kota Tarakan.

c. System Model

Bagian system model menggambarkan arsitektur server yang melayani transaksi data aplikasi Deliv. Gambar 6, merupakan desain arsitektur server sekarang ini. Server terbagi menjadi tiga stack, yaitu stack production untuk melayani transaksi bisnis di produksi atau aplikasi rilis, stack debug untuk melayani uji coba transaksi pada proses pengembangan, dan stack stagging untuk melakukan kontrol terhadap dua stack sebelumnya. Server bekerja dengan webservice lain untuk menangani transaksi yaitu Slack, Google, Zenzifa, Sepulsa, dan IPN.

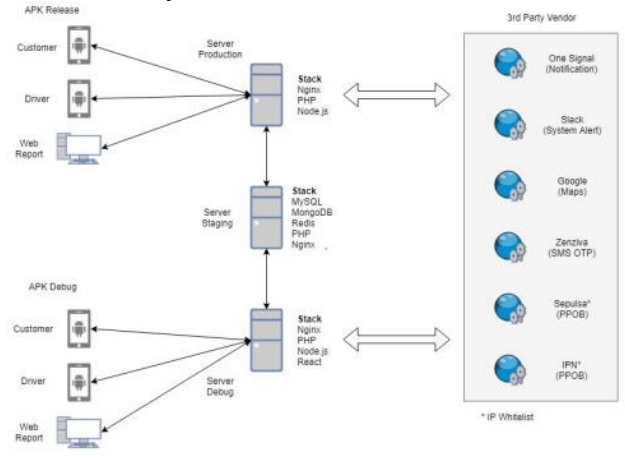

Gambar 6. Arsitektur Server Aplikasi Deliv

\section{d. Technology Model}

Membahas mengenai skema alur data dan teknologi yang digunakan pada aplikasi Deliv milik PT. Deliv Tehnologi Indoraya. Gambar 7 menunjukkan alur transaksi data pada saat ini. Client terdiri dari dua platform yaitu Android dan web. Webserver yang digunakan adalah Nginx dengan Node.js sebagai REST API utamanya. Database yang digunakan adalah MySQL, MongoDB, dan Redis. Perubahan pada project dikelola dengan VCS Git yang tertanam pada server.

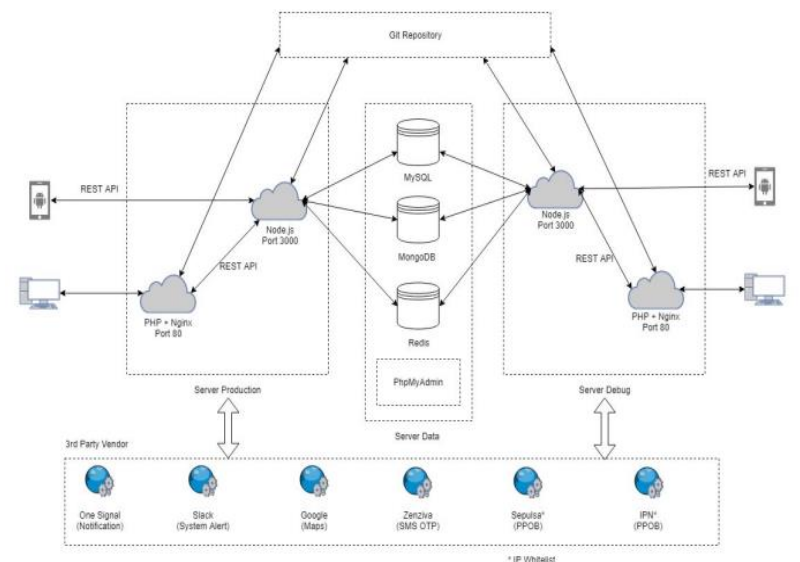

Gambar 7 Arsitektur Transaksi Data Aplikasi Deliv 


\subsection{Who}

Kolom who membahas tentang sumber daya manusia yang berperan penting dalam proses bisnis dan pengembangan di PT. Deliv Tehnology Indoraya. Bagian-bagian yang akan dijelaskan yaitu scope, business model, dan system model.

a. Scope

Daftar unit organisasi yang berperan dalam proses bisnis dan pengembangan di PT. Deliv Tehnology Indoraya adalah sebagai berikut:

1. Penasihat

2. Board of Director (BOD)

3. Chief Excutive Officer (CEO)

4. Chief Technology Officer (CTO)

5. Chief Financial Officer (CFO)

6. Wakil Presiden Pemasaran

7. Manager CTO

8. Manager CFO

9. Manager WP Pemasaran

10. Staf CTO

11. Staf CFO

12. Staf WP Pemasaran

b. Bussines Model

Pada bagian Bussiness model kerangka struktur organisasi PT. Deliv Technology Indoraya dalam proses bisnis dan pengembangan digambarkan pada gambar 8 .

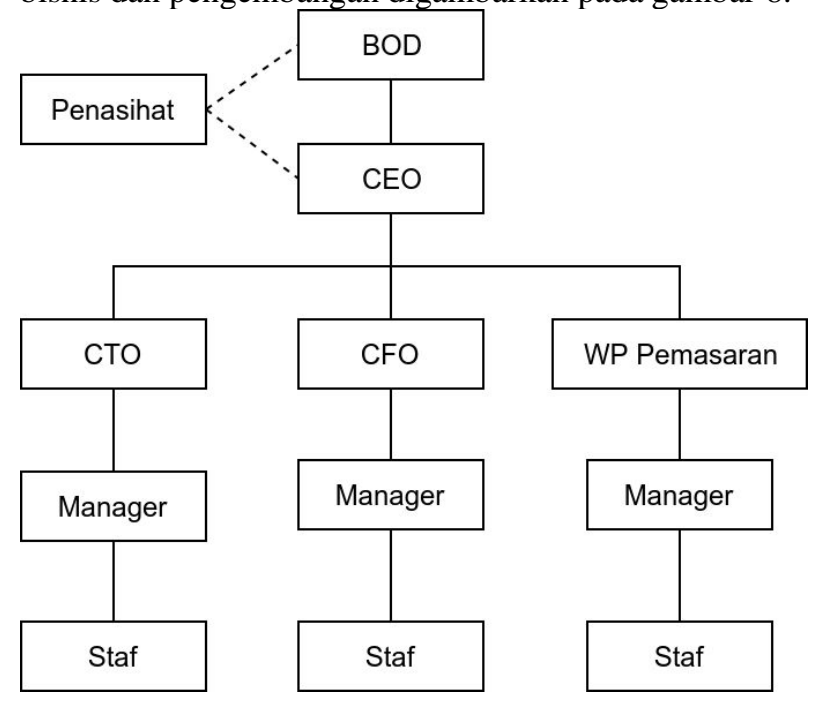

Gambar 8. Struktur Organisasi

c. System Model

Merupakan penjelasan kerangka kerja pada setiap entitas yang ada pada uraian Kerja Struktur Organisasi di PT. Deliv Technology Indoraya.

\subsection{When}

Pada kolom When, bagian yang dijelaskan yaitu scope, Business model, System model, dan functioning system.

a. Scope

Membahas proses-proses bisnis dan pengembangan yang terjadi di PT. Deliv Tehnology Indoraya. Uraian proses bisnis dan pengembangan yang terjadi secara global yaitu seperti berikut:

1) Pendaftaran Driver

2) Pendaftaran User

3) Pendaftaran Mitra Defood (Restoran)
4) Transaksi Deride

5) Transaksi Defood

6) Transaksi Depayment

7) Transaksi Deexpress

8) Pembaruan Aplikasi Berkala

b. Bussines Model

Membahas mengenai detail major event (scope) proses bisnis dan pengembangan yang terjadi di PT. Deliv Tehnologi Indoraya.

c. System Model

Pembahasan dalam system model menguraikan pengaturan waktu berdasarkan periode waktu tertentu untuk setiap kegiatan PT. Deliv Tehnologi Indoraya.

d. Functioning system

Proses bisnis dan pengembangan dalam PT. Deliv Tehnology Indoraya secara keseluruhan tergambar dalam kalender rencana bulanan perusahaan.

\subsection{Why}

Pembahasan kolom Why, menguraikan kegiatan bisnis adalah scope dan enterprise model.

a. Scope

PT. Deliv Tehnologi Indoraya bersatu dalam kesamaan visi, misi, dan tujuan yang tertuang dalam pernyataan-pernyataan sebagai mana yang tertuang pada anggaran rumah tangga, PT. Deliv Tehnologi Indoraya adalah salah satu perusahaan teknologi yang memberikan layanan di bidang teknologi mempunyai Visi dan Misi sebagai berikut:

1. Visi

Membantu memperbaiki struktur transportasi di Indonesia, memberikan kemudahan bagi masyarakat ketika melakukan pekerjaan sehari-hari seperti membeli makanan, memesan transportasi, pengiriman dokumen, belanja harian, dengan menggunakan layanan fasilitas kurir, serta turut mensejahterakan kehidupan tukang ojek di Indonesia.

2. Misi

a. Menjadikan PT. Deliv Tehnologi Indoraya sebagai jasa transportasi tercepat dalam melayani kebutuhan masyarakat Indonesia.

b. Menjadikan PT. Deliv Tehnologi Indoraya sebagai acuan pelaksanaan kepatuhan dan tata kelola struktur transportasi yang baik dengan menggunakan kemajuan teknologi.

c. Meningkatkan kepedulian dan tanggung jawab terhadap lingkungan dan sosial

d. Memberikan layanan prima dan solusi yang bernilai tambah kepada pelanggan.

3. Tujuan didirikan

Tujuan didirikannya PT. Deliv Tehnologi Indoraya adalah untuk mengembangkan jasa transportasi yang banyak di jumpai di masyarakat seperti ojek dan taksi dengan menggunakan teknologi agar para pelaku jasa transportasi menjadi lebih baik pendapatannya dan masyarakat dapat lebih mudah dan cepat dalam menggunakan jasa transportasi.

\section{KESIMPULAN}

Dari hasil pemodelan arsitektur enterprise dengan menggunakan Zachman Framework ini dapat diambil beberapa kesimpulan bahwa berdasarkan hasil analisis sistem informasi bisnis PT. Deliv Tehnologi Indoraya 
dengan metode Enterprise Architecture Zachman Framework membantu organisasi dalam memiliki dasar sistem informasi yang terintegrasi dengan baik. hasil pengembangan sistem informasi di perusahaan, Enterprise Architecture di PT. Deliv Tehnologi Indoraya sebagai landasan agar tidak keluar dari tujuan perusahaan dan tidak menghilangkan integrasi antar unit bisnis perusahaan. Zachman Framework digunakan untuk memodelkan Enterprise Architecture yang menggambarkan setiap langkah pengerjaan dengan lebih mudah dimengerti dan hal-hal apa saja yang harus dibuat sudah dituliskan secara eksplisit. Dari hasil penelitian ini penulis menyarankan sebagai berikut: Model Zachman Framework ini bukan Enterprise Architecture final dari PT. Deliv Tehnologi Indoraya, namun terus melakukan pengembangan sistem secara berkelanjutan. Peningkatan infrastruktur sebagai pendukung teknologi kegiatan bisnis. Pengembangan penelitian ini ditindak lanjuti dalam sistem penilaian kinerja mitra digambarkan dalam Balanced Scored Card dan pengembangan Mutu menggunakan Framework COBIT.

\section{REFERENSI}

[1] Ross, J., Weill, P., dan Robertson, A. 2006. Enterprise Architecture As Strategy. Boston, Massachusetts, U.S.A: Harvard Business School Press.

[2] Setiawan, B. E. 2009. Pemilihan EA Framework. Prosiding SNATI, ISSN: 1907-5022, B114-B119. Yogyakarta, D.I.Yogyakarta, Indonesia: Universitas Islam Indonesia.

[3] Dittman, Whitten Bentley. 2004. System Analysis And Design Methods. McGraw-Hill Companies.

[4] Irmanyani, W. (2015). Enterprise Architecture Planning (EAP) menggunakan togaf ADM pada dinas cipta karya, tata ruang dan kebersihan kabupaten kubu raya. Jurnal Katulistiwa Informatika, 3, 94-105.

[5] Hizbullah, I., Nugroho, E., \& Santosa, P. (2015). Model perencanaan strategis SI/TI perguruan tinggi menggunakan framework togaf (studi kasus stkip kie raha). Seminar Nasional Ilmu Komputer, 189-193.

[6] Saputra, D. (2015). Perancangan enterprise architecture zachman framework untuk jasa layanan pasang baru dan tambah daya listrik pada perusahaan jasa listrik swasta. Jurnal Katulistiwa Informatika, 3, 124.

[7] Chung, dan McLeod, G. 2002. Enterprise architecture, implementation, and infrastructure management. Annual Hawaii International Conference on System Sciences, Hawaii.

[8] Subagio, R. (2012). Pemodelan arsitektur enterprise STMIK CIC Cirebon menggunakan enterprise architecture planning. Jurnal Sistem Informasi, 7, 173185.

[9] Pramana, D., \& Yuningsih, L. (2013). Implementasi Zachman Framework pada Sistem Reservasi Online Studi kasus Hotel XYZ. STMIK AMIKOM

[10] Haag, Stephen; \& Cummings, Meave. 2008. Information Systems Essentials. Second Edition. McGraw-Hill, New York.

[11] Gata, Windu dan Gata, Grace. 2013. Sukses Membangun Aplikasi Penjualan dengan Java. Elex Media Komputindo, Jakarta. 